\title{
TOUGHREACT Testing in High Ionic Strength Brine Sandstone Systems
}

\author{
Tianfu $X u$
}

Earth Sciences Division, Lawrence Berkeley National Laboratory, Berkeley, CA 94720

\section{Introduction}

Deep saline formations and oil and gas reservoirs often contain concentrated brine solutions of ionic strength greater than 1 (I > $1 \mathrm{M})$. Geochemical modeling, involving high ionic strength brines, is a challenge. In the original TOUGHREACT code (Xu et al., 2004; Xu et al., 2006), activity coefficients of charged aqueous species are computed using an extended Debye-Huckel (DH) equation and parameters derived by Helgeson et al. (1981). The DH model can deal with ionic strengths from dilute to moderately saline water (up to 6 molal for an $\mathrm{NaCl}$-dominant solution). The equations implemented for the DH model are presented in Appendix A. During the course of the Yucca Mountain project, a Pitzer ion-interaction model was implemented into TOUGHREACT. This allows the application of this simulator to problems involving much more concentrated aqueous solutions, such as those involving geochemical processes in and around highlevel nuclear waste repositories where fluid evaporation and/or boiling is expected to occur (Zhang et al., 2007). The Pitzer ion-interaction model, which we refer to as the Pitzer virial approach, and associated ion-interaction parameters have been applied successfully to study non-ideal concentrated aqueous solutions. The formulation of the Pitzer model is presented in Appendix B; detailed information can be founded in Zhang et al. (2007).

For $\mathrm{CO}_{2}$ geological sequestration, the Pitzer ion-interaction model for highly concentrated brines was incorporated into TOUGHREACT/ECO2N, then was tested and compared with a previously implemented extended Debye-Hückel (DH) ion activity model. The comparison was made through a batch geochemical system using a Gulf Coast sandstone saline formation. 


\section{Problem Setup}

The batch model uses initial saturations of 0.5 for $\mathrm{scCO}_{2}$ and 0.5 for liquid (water). The water chemical composition (Table 1), a NaCl-dominated brine with an ionic strength of about $1.5 \mathrm{M}$, was taken from a sample from the Frio test site. Two formation temperatures of $45^{\circ}$ and $75^{\circ} \mathrm{C}$ were used, which may represent temperatures at depths of about 1 and $2 \mathrm{~km}$, given a land surface temperature of $15^{\circ} \mathrm{C}$ and a geothermal gradient of $30^{\circ} \mathrm{C} / \mathrm{km}$. The initial mineral composition used is presented in Table 2, which were taken from $\mathrm{Xu}$ et al. (2007). The rock mineralogical composition may be representative of US Gulf Coast sandstone formations. The batch geochemical simulation was performed for 50,000 years.

Table 1. Initial total dissolved component concentrations for reactive transport simulations. Iron is the sum of $\mathrm{Fe}^{2+}, \mathrm{Fe}^{3+}$ and their related complexes. Carbon is the sum of $\mathrm{CO}_{2}(\mathrm{aq}), \mathrm{CH}_{4}(\mathrm{aq})$, and their related species such as $\mathrm{HCO}_{3}^{-}$and acetic acid(aq). Sulfur is the sum of sulfate and sulfide species

\begin{tabular}{|l|l|}
\hline \multicolumn{1}{|c|}{ Component } & \multicolumn{1}{|c|}{ Concentration } \\
& \multicolumn{1}{|c|}{$\left(\mathrm{mol} / \mathrm{kg} \mathrm{H}_{2} \mathrm{O}\right)$} \\
\hline $\mathrm{Ca}^{2+}$ & $6.6 \times 10^{-2}$ \\
$\mathrm{Mg}^{2+}$ & $2.2 \times 10^{-2}$ \\
$\mathrm{Na}^{+}$ & 1.35 \\
$\mathrm{~K}^{+}$ & $4.53 \times 10^{-3}$ \\
$\mathrm{Iron}$ & $4.63 \times 10^{-4}$ \\
$\mathrm{SiO}_{2}(\mathrm{aq})$ & $2.50 \times 10^{-4}$ \\
$\mathrm{Carbon}^{-4}$ & $5.04 \times 10^{-2}$ \\
$\mathrm{Sulfur}$ & $4.20 \times 10^{-5}$ \\
$\mathrm{Al}^{3+}$ & $1.56 \times 10^{-8}$ \\
$\mathrm{Cl}^{-}$ & 1.49 \\
$\mathrm{O}_{2}(\mathrm{aq})$ & $4.88 \times 10^{-68}$ \\
$\mathrm{pH}$ & 6.7 \\
$\mathrm{Temperature}$ & $75^{\circ} \mathrm{C}$ \\
& \\
\hline
\end{tabular}


Table 2. Initial mineral volume fractions and possible secondary mineral phases used in the simulations.

\begin{tabular}{|l|l|l|l|}
\hline \multirow{2}{*}{ Mineral } & \multirow{2}{*}{ Chemical formula } & \multicolumn{2}{|c|}{ Volume percent } \\
\cline { 3 - 4 } & & & of solid \\
\hline Primary: & & & \\
\hline Quartz & $\mathrm{SiO}_{2}$ & 58 & 40.6 \\
\hline Kaolinite & $\mathrm{Al}_{2} \mathrm{Si}_{2} \mathrm{O}_{5}(\mathrm{OH})_{4}$ & 2.02 & 1.41 \\
\hline Calcite & $\mathrm{CaCO}_{3}$ & 1.93 & 1.35 \\
\hline Illite & $\mathrm{K}_{0.6} \mathrm{Mg}_{0.25} \mathrm{Al}_{1.8}\left(\mathrm{Al}_{0.5} \mathrm{Si}_{3.5} \mathrm{O}_{10}\right)(\mathrm{OH})_{2}$ & 1.0 & 0.7 \\
\hline Oligoclase & $\mathrm{Ca}_{0.2} \mathrm{Na}_{0.8} \mathrm{Al}_{1.2} \mathrm{Si}_{2.8} \mathrm{O}_{8}$ & 19.8 & 13.86 \\
\hline K-feldspar & $\mathrm{KAlSi}_{3} \mathrm{O}_{8}$ & 8.2 & 5.74 \\
\hline Na-smectite & $\mathrm{Na}_{0.290} \mathrm{Mg}_{0.26} \mathrm{Al}_{1.77} \mathrm{Si}_{3.97} \mathrm{O}_{10}(\mathrm{OH})_{2}$ & 4 & 2.8 \\
\hline Chlorite & $\mathrm{Mg}_{2.5} \mathrm{Fe}_{2.5} \mathrm{Al}_{2} \mathrm{Si}_{3} \mathrm{O}_{10}(\mathrm{OH})_{8}$ & 4.55 & 3.19 \\
\hline Hematite & $\mathrm{Fe}_{2} \mathrm{O}_{3}$ & 0.5 & 0.35 \\
\hline Porosity & & ---- & 30 \\
\hline Secondary: & & & \\
\hline Anhydrite & $\mathrm{CaSO}_{4}$ & & \\
\hline Magnesite & $\mathrm{MgCO}_{3}$ & & \\
\hline Dolomite & $\mathrm{CaMg}_{2}\left(\mathrm{CO}_{3}\right)_{2}$ & & \\
\hline Low-albite & $\mathrm{NaAlSi}_{3} \mathrm{O}_{8}$ & & \\
\hline Siderite & $\mathrm{FeCO}_{3}$ & & \\
\hline Ankerite & $\mathrm{CaMg}_{0.3} \mathrm{Fe}_{0.7}\left(\mathrm{CO}_{3}\right)_{2}$ & & \\
\hline Dawsonite & $\mathrm{NaAlCO}_{3}(\mathrm{OH})_{2}$ & & \\
\hline Ca-smectite & $\mathrm{Na}_{0.145} \mathrm{Mg}_{0.26} \mathrm{Al}_{1.77} \mathrm{Si}_{3.97} \mathrm{O}_{10}(\mathrm{OH})_{2}$ & & \\
\hline Alunite & $\mathrm{KAl}_{3}\left(\mathrm{OH}_{6}\left(\mathrm{SO}_{4}\right)_{2}\right.$ & & \\
\hline Pyrite & $\mathrm{FeS}_{2}$ & & \\
\hline
\end{tabular}

Mineral dissolution and precipitation are considered under kinetic conditions. A general form of rate expression is used, which is based on transition state theory (TST) (Lasaga et al., 1994):

$$
r=k A\left[1-\left(\frac{Q}{K}\right)^{\theta}\right]^{\eta}
$$

where $\mathrm{r}$ is the kinetic rate (units of moles per second; positive values indicate dissolution, and negative values precipitation), $\mathrm{k}$ is the rate constant (moles per unit mineral surface 
area and unit time) which is temperature dependent, $\mathrm{A}$ is the specific reactive surface area per $\mathrm{kg} \mathrm{H}_{2} \mathrm{O}, \mathrm{K}$ is the equilibrium constant for the mineral-water reaction written for the destruction of one mole of mineral, and $\mathrm{Q}$ is the reaction quotient. The parameters $\theta$ and $\eta$ must be determined by experiment, but are commonly set equal to unity when experimental quantification is unavailable. The precipitation of secondary minerals is represented using the same kinetic expression as for dissolution.

For many minerals, the kinetic rate constant $\mathrm{k}$ can be summed from three mechanisms (Lasaga et al., 1994; Palandri and Kharaka, 2004):

$$
\begin{array}{r}
k=k_{n u}^{25} \exp \left[\frac{-E_{n u}}{R}\left(\frac{1}{T}-\frac{1}{298.15}\right)\right]+k_{H}^{25} \exp \left[\frac{-E_{H}}{R}\left(\frac{1}{T}-\frac{1}{298.15}\right)\right] a_{H}^{n_{H}} \\
+k_{O H}^{25} \exp \left[\frac{-E_{O H}}{R}\left(\frac{1}{T}-\frac{1}{298.15}\right)\right] a_{O H}^{n_{O H}}
\end{array}
$$

where subscripts $\mathrm{nu}, \mathrm{H}$, and $\mathrm{OH}$ indicate neutral, acid, and base mechanisms, respectively, $\mathrm{E}$ is the activation energy, $\mathrm{k}^{25}$ is the rate constant at $25^{\circ} \mathrm{C}, \mathrm{R}$ is the universal gas constant, $\mathrm{T}$ is absolute temperature, $\mathrm{a}$ is the activity of the species; and $\mathrm{n}$ is a power term (constant). Notice that parameters $\theta$ and $\eta$ (see Eq. 1) are assumed to be the same for each mechanism, and, for reasons noted above, are set to unity in the present work. Mineral dissolution and precipitation rates are a product of the kinetic-rate constant and reactive surface area as represented by Eq. 1. The parameters used for the kinetic rate expression are given in Table 3, which were taken from Xu et al (2007). 
Table 3. Parameters for calculating kinetic rate constants of minerals. Note that: (1) all rate constants are listed for dissolution (2) A is specific surface area, $\mathrm{k}^{25}$ is kinetic constant at $25^{\circ} \mathrm{C}, \mathrm{E}$ is activation energy, and $\mathrm{n}$ is the power term (Eq. 2); (3) the power terms $\mathrm{n}$ for both acid and base mechanisms are with respect to $\mathrm{H}^{+}$, (4) for pyrite, the neutral mechanism has $\mathrm{n}$ with respect to $\mathrm{O}_{2}(\mathrm{aq})$, the acid mechanism has two species involved: one $\mathrm{n}$ with respect to $\mathrm{H}^{+}$and another $\mathrm{n}$ with respect to $\mathrm{Fe}^{3+}$.

\begin{tabular}{|c|c|c|c|c|c|c|c|c|c|}
\hline \multirow[t]{3}{*}{ Mineral } & \multirow{3}{*}{$\begin{array}{l}A \\
\left(\mathrm{~cm}^{2} / \mathrm{g}\right)\end{array}$} & \multicolumn{8}{|c|}{ Parameters for kinetic rate law } \\
\hline & & \multicolumn{2}{|c|}{ Neutral mechanism } & \multicolumn{3}{|c|}{ Acid mechanism } & \multicolumn{3}{|c|}{ Base mechanism } \\
\hline & & $\begin{array}{l}k^{25} \\
\left(\mathrm{~mol} / \mathrm{m}^{2} / \mathrm{s}\right)\end{array}$ & $\begin{array}{l}E \\
(K J \\
/ m o l)\end{array}$ & $k^{25}$ & $E$ & $n\left(H^{+}\right)$ & $k^{25}$ & $E$ & $n\left(H^{+}\right)$ \\
\hline Calcite & \multicolumn{9}{|c|}{ At local equilibrium } \\
\hline Quartz & 9.1 & $1.023 \times 10^{-14}$ & 87.7 & & & & & & \\
\hline Kaolinite & 108.7 & $6.918 \times 10^{-14}$ & 22.2 & $4.898 \times 10^{-12}$ & 65.9 & 0.777 & $8.913 \times 10^{-18}$ & 17.9 & -0.472 \\
\hline Illite & 108.7 & $1.660 \times 10^{-13}$ & 35 & $1.047 \times 10^{-11}$ & 23.6 & 0.34 & $3.020 \times 10^{-17}$ & 58.9 & -0.4 \\
\hline Oligoclase & 9.1 & $1.445 \times 10^{-12}$ & 69.8 & $2.138 \times 10^{-10}$ & 65 & 0.457 & & & \\
\hline K-feldspar & 9.1 & $3.890 \times 10^{-13}$ & 38 & $8.710 \times 10^{-11}$ & 51.7 & 0.5 & $6.310 \times 10^{-12}$ & 94.1 & -0.823 \\
\hline Na-smectite & 108.7 & $1.660 \times 10^{-13}$ & 35 & $1.047 \times 10^{-11}$ & 23.6 & 0.34 & $3.020 \times 10^{-17}$ & 58.9 & -0.4 \\
\hline Chlorite & 9.1 & $3.02 \times 10^{-13}$ & 88 & $7.762 \times 10^{-12}$ & 88 & 0.5 & & & \\
\hline Hematite & 12.9 & $2.512 \times 10^{-15}$ & 66.2 & $4.074 \times 10^{-10}$ & 66.2 & 1 & & & \\
\hline Magnesite & 9.1 & $4.571 \times 10^{-10}$ & 23.5 & $4.169 \times 10^{-7}$ & 14.4 & 1 & & & \\
\hline Dolomite & 9.1 & $2.951 \times 10^{-8}$ & 52.2 & $6.457 \times 10^{-4}$ & 36.1 & 0.5 & & & \\
\hline Low-albite & 9.1 & $2.754 \times 10^{-13}$ & 69.8 & $6.918 \times 10^{-11}$ & 65 & 0.457 & $2.512 \times 10^{-16}$ & 71 & -0.572 \\
\hline Siderite & 9.1 & $1.260 \times 10^{-9}$ & 62.76 & $6.457 \times 10^{-4}$ & 36.1 & 0.5 & & & \\
\hline Ankerite & 9.1 & $1.260 \times 10^{-9}$ & 62.76 & $6.457 \times 10^{-4}$ & 36.1 & 0.5 & & & \\
\hline Dawsonite & 9.1 & $1.260 \times 10^{-9}$ & 62.76 & $6.457 \times 10^{-4}$ & 36.1 & 0.5 & & & \\
\hline Ca-smectite & 108.7 & $1.660 \times 10^{-13}$ & 35 & $1.047 \times 10^{-11}$ & 23.6 & 0.34 & $3.020 \times 10^{-17}$ & 58.9 & -0.4 \\
\hline Alunite & 9.1 & $1.000 \times 10^{-12}$ & 57.78 & & & & $1.000 \times 10^{-12}$ & 7.5 & -1.0 \\
\hline Pyrite & 12.9 & $\begin{array}{l}\mathrm{k}_{25}=2.818 \times 1 \\
\mathrm{E}_{\mathrm{a}}=56.9 \\
\mathrm{n}\left(\mathrm{O}_{2}(\mathrm{aq})\right)=0\end{array}$ & & $\begin{array}{l}\mathrm{k}_{25}=3.02 \times 10 \\
\mathrm{E}_{\mathrm{a}}=56.9 \\
\mathrm{n}\left(\mathrm{H}^{+}\right)=-0.5,\end{array}$ & $\mathrm{n}(\mathrm{F}$ & $+=0.5$ & & & \\
\hline
\end{tabular}




\section{Results}

The water composition presented in Table 1 has an ionic strength of $1.5 \mathrm{M}$. The simulations was performed directly using this initial water. The comparison results are presented in Figures 1-4. For a temperature of $45^{\circ} \mathrm{C}$, $\mathrm{pH}$ obtained from the Pitzer model is slightly higher than $\mathrm{pH}$ from the $\mathrm{DH}$ model (Figure 1a). For $75^{\circ} \mathrm{C}, \mathrm{pH}$ values from both models are very close (Figure $1 \mathrm{~b}$ ). At $45^{\circ} \mathrm{C}$, total dissolved $\mathrm{CO}_{2}$ concentrations from the Pitzer model are quite a bit lower than those from the DH model (Figure 2a). For $75^{\circ} \mathrm{C}$, the total dissolved $\mathrm{CO}_{2}$ of Pitzer model is slightly lower than that of the $\mathrm{DH}$ model (Figure 2b). Amounts of siderite precipitation predicted by both models for both temperatures are very close (Figure 3). Dawsonite precipitation obtained from the Pitzer model is slightly higher than that from the DH model (Figure 4). The Pitzer model requires six times more computing time than the $\mathrm{DH}$ model for this test problem.

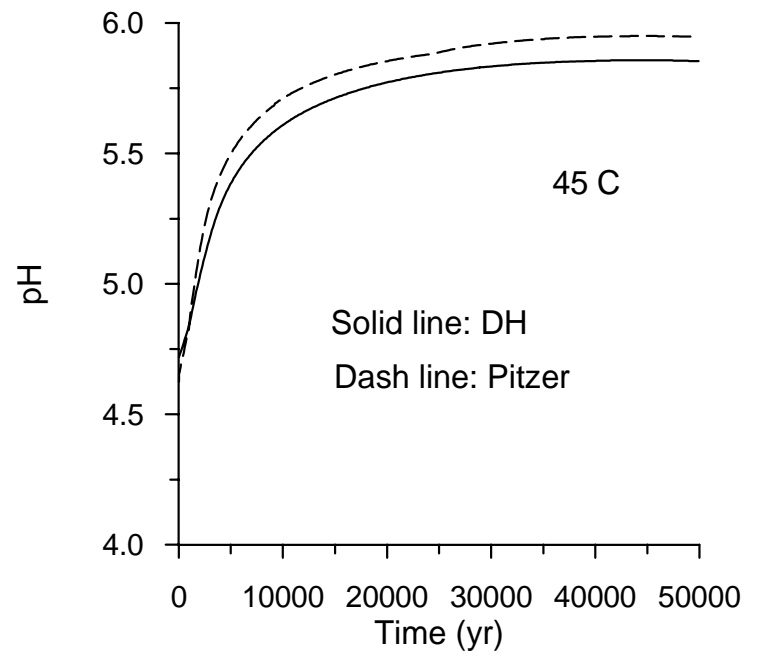

(a) $45{ }^{\circ} \mathrm{C}$

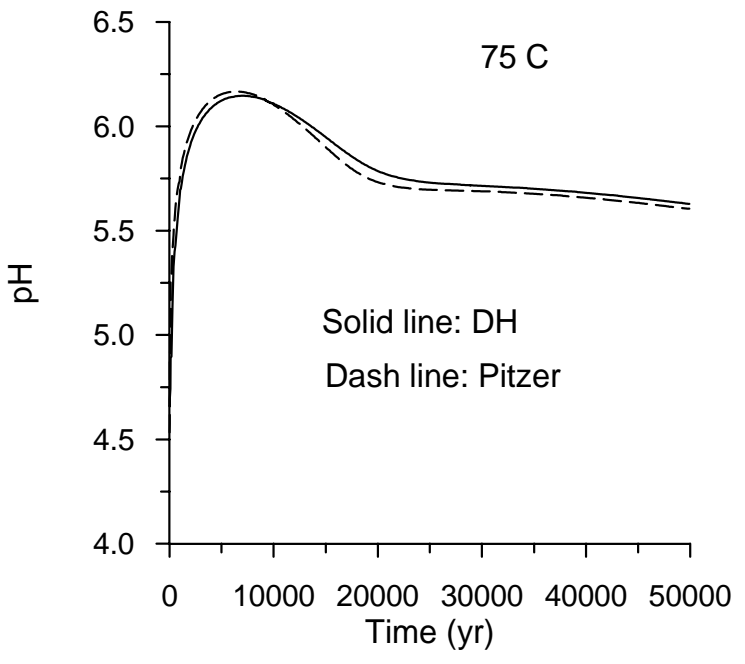

(b) $75^{\circ} \mathrm{C}$

Figure 1. Comparison of $\mathrm{pH}$ evolution obtained from the extended Debye-Hückel (DH) and the Pitzer ion activity models. 


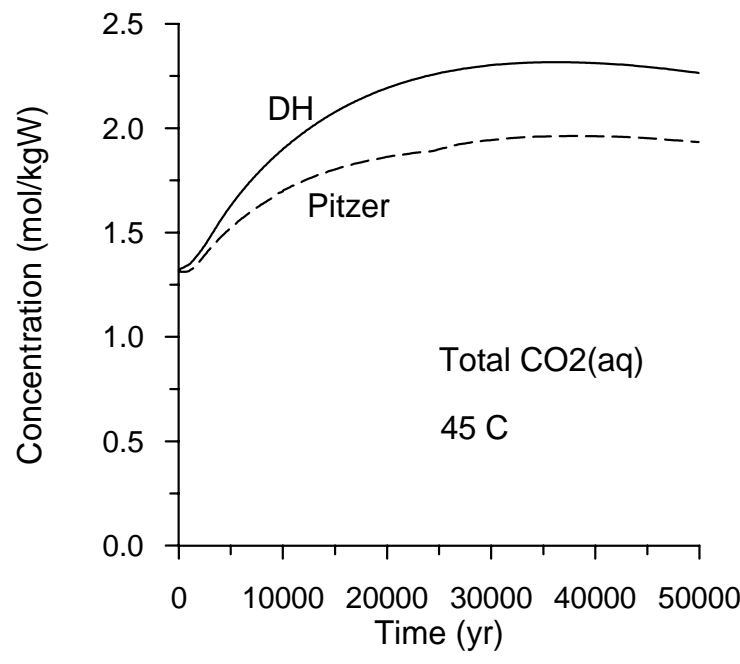

(a) $45^{\circ} \mathrm{C}$

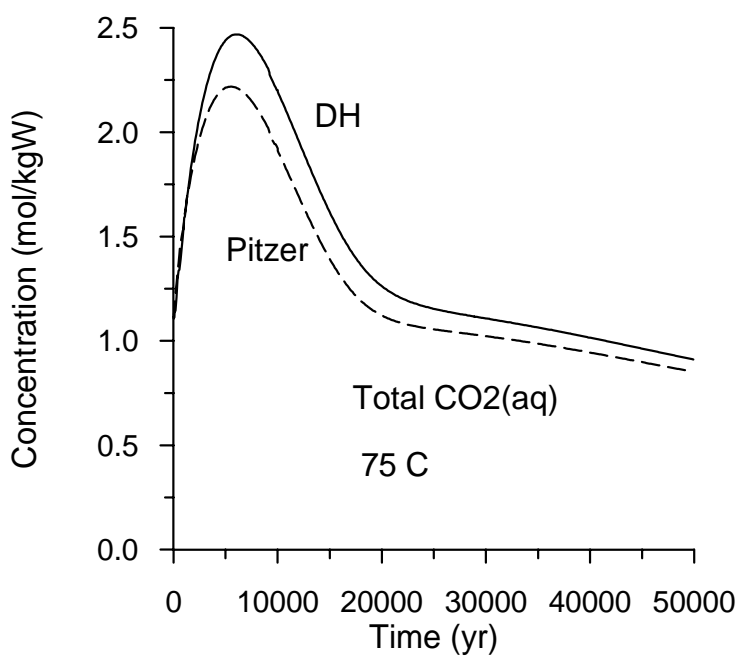

(b) $75^{\circ} \mathrm{C}$

Figure 2. Comparison of total dissolved $\mathrm{CO}_{2}$ concentrations obtained from the $\mathrm{DH}$ and the Pitzer models.

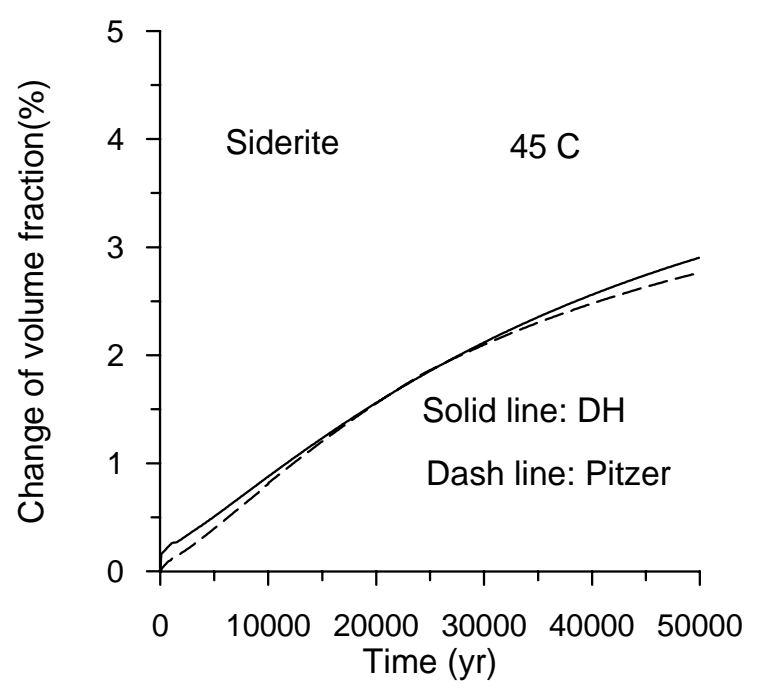

(a) $45{ }^{\circ} \mathrm{C}$

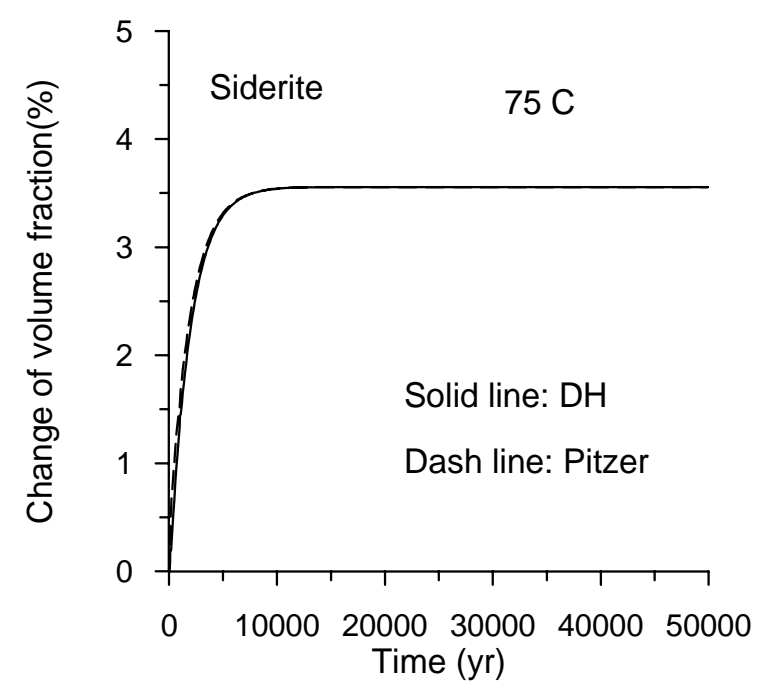

(b) $75{ }^{\circ} \mathrm{C}$

Figure 3. Comparison of siderite precipitations obtained from the DH and the Pitzer models. 


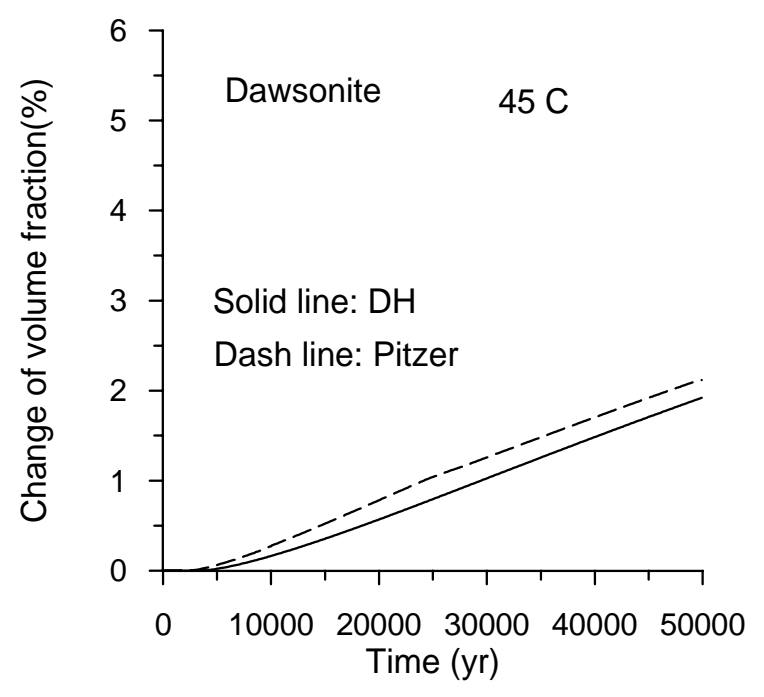

(a) $45{ }^{\circ} \mathrm{C}$

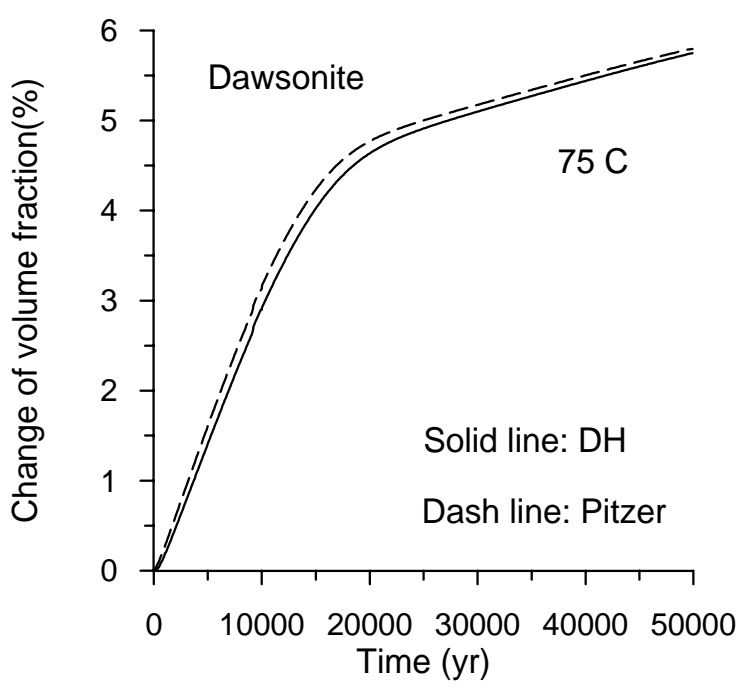

(b) $75{ }^{\circ} \mathrm{C}$

Figure 4. Comparison of dawsonite precipitations obtained from the DH and the Pitzer models.

\section{Conclusions and Recommendations}

The predicted $\mathrm{pH}$ and dissolved concentrations obtained from the $\mathrm{DH}$ and Pitzer models are somewhat different. Amounts of $\mathrm{CO}_{2}$ trapped by carbonate precipitation are quite similar because mineral dissolution and precipitation are kinetically-controlled. The $\mathrm{DH}$ model is probably adequate for moderately higher NaCl-dominant brine $(1.5 \mathrm{M}$ in the test case, most encountered in saline aquifers). For studies on water composition and density changes for highly concentrated brine, the Pitzer model should be used. It should be pointed out that currently available data for the Pitzer ion-interaction model are very limited, and need further study. In addition, possible effects of ionic strength on kinetics of mineral dissolution and precipitation are not clear and require investigation.

Acknowledgement. The author thanks Karsten Pruess for reviews of the manuscript. This work was supported by the Zero Emission Research and Technology project (ZERT), of the U.S. Department of Energy under Contract No. DE-AC02-05CH11231 with Lawrence Berkeley National Laboratory. 


\section{REFERENCES}

Harvie, C.E., N. Moller, and J. A. Weare, The prediction of mineral solubilities in natural waters: The $\mathrm{Na}-\mathrm{K}-\mathrm{Mg}-\mathrm{Ca}-\mathrm{H}-\mathrm{Cl}-\mathrm{SO}_{4}-\mathrm{OH}-\mathrm{HCO}_{3}-\mathrm{CO}_{3}-\mathrm{H}_{2} \mathrm{O}$-system to high ionic strengths at $25{ }^{\circ} \mathrm{C}$, Geochim. Cosmochim. Acta, v. 48, p. 723-751, 1984.

Helgeson, A.C., D.A. Kirkham, and G. C. Flowers, Thermodynamic prediction of the thermodynamic behaviour of aqueous electrolytes at high pressure and temperature: IV. Calculations of activity coefficients, osmotic coefficients and apparent molal and standard and relative partial molal properties to $600^{\circ} \mathrm{C}$ and $5 \mathrm{~KB}, A m$. J. Science, v. 281, 1249-1516, 1981.

Lasaga, A.C., J.M. Soler, J. Ganor, T.E. Burch, K.L. Nagy, Chemical weathering rate laws and global geochemical cycles, Geochimica et Cosmochimica Acta, v. 58, p.2361-2386, 1994

Pitzer, K.S., Ion interaction approach: Theory and data correlation. In Activity Coefficients in Electrolytes Solutions, edited by K. S. Pitzer, $2^{\text {nd }}$ ed., CRC Press, 75 1991.

Robinson, R. A., and Stokes, R. H., Electrolyte Solutions, the Measurement and Interpretation of Conductance, Chemical Potential and Diffusion in Solutions of Simple Electrolytes, $2^{\text {nd }}$ Edition, London, England: Butterworths \& Company, 1965.

Shock, E. L., Helgeson, H. C., and Sverjensky, D. A., Calculation of the thermodynamic and transport properties of aqueous species at high pressures and temperatures: Standard partial molal properties of inorganic neutral species, Geochim. Cosmochim. Acta, v. 53 (9), p. 2157-2183, 1989.

Xu, T., E.L. Sonnenthal, N. Spycher, and K. Pruess, TOUGHREACT user's guide: A simulation program for non-isothermal multiphase reactive geochemical transport in variable saturated geologic media, Lawrence Berkeley National Laboratory Report LBNL-55460, pp. 192, 2004.

$\mathrm{Xu}$, T., E.L. Sonnenthal, N. Spycher, and K. Pruess, TOURGHREACT: A simulation program for non-isothermal multiphase reactive geochemical transport in variably saturated geologic media. Computer \& Geosciences, v.32, p.145-165, 2006.

$\mathrm{Xu}$, T., J. A. Apps, K. Pruess, and H. Yamamoto, Numerical modeling of injection and mineral trapping of $\mathrm{CO} 2$ with $\mathrm{H} 2 \mathrm{~S}$ and $\mathrm{SO} 2$ in a sandstone formation, Chemical Geology, v.242/3-4, p.319-346, 2007.

Zhang, G., N. Spycher, T. Xu, E. Sonnenthal, and C. Steefel, Reactive geochemical transport modeling of concentrated aqueous solutions: supplement to TOUGHREACT User's Guide for the Pitzer ion-interaction model, Lawrence Berkeley National Laboratory, LBNL-62718, Berkeley, California, 2007. 


\section{Appendix A: Debye-Huckel Model for calculation of activity coefficients of aqueous species implemented in TOUGHREACT}

Activity coefficients of charged aqueous species are computed using an extended Debye-Huckel equation and parameters derived by Helgeson et al. (1981) (HKF). The assumption is made that the dominant cation and anion in solution are sodium and chloride, respectively, so that HKF Equation 298 can be used directly, as follows:

$$
\begin{aligned}
\log \left(\gamma_{j}\right)=-\frac{\mathrm{A}_{\gamma} z_{j}^{2} \mathrm{I}^{0.5}}{\Lambda}+\log (1+0.0180153 \mathrm{~m} *)- \\
{\left[\omega_{j} \mathrm{~b}_{\mathrm{NaCl}}+\mathrm{b}_{\mathrm{Na}^{+}, \mathrm{Cl}}-0.19\left(\left|z_{j}\right|-1\right)\right] \mathrm{I} }
\end{aligned}
$$

and

$$
\begin{aligned}
& \Lambda=1+\stackrel{a}{B_{\gamma}} \overline{\mathrm{I}}^{1 / 2} \\
& \omega_{j}=\eta \frac{\mathrm{z}_{j}^{2}}{\mathrm{r}_{\mathrm{e}, j}}
\end{aligned}
$$

where the subscript $j$ refers to each ion, $\gamma$ is the activity coefficient of the ion, DebyeHuckel parameters $\mathrm{b}_{\mathrm{Na}}{ }^{+}{ }_{\mathrm{Cl}}^{-}, \mathrm{b}_{\mathrm{NaCl}}, \mathrm{A} \gamma$ and $\mathrm{B} \gamma$ are given in HKF Tables 1, 29, and 30, Debye-Huckel parameter å is calculated as discussed below, $\mathrm{z}$ is the ion electric charge, I is taken as the true ionic strength of the solution, $\omega$ is the Born coefficient, $\eta$ is a constant equal to 1.66027 ( $\AA \mathrm{cal} / \mathrm{mol})$, and $\mathrm{r}_{\mathrm{e}, \mathrm{j}}$ is the ion effective ionic radius given in HKF Table 3 or estimated as shown on Table A.1 when not available.

Debye-Huckel parameters $\mathrm{b}_{\mathrm{Na}}{ }^{+}{ }_{\mathrm{Cl}}^{-}, \mathrm{b}_{\mathrm{NaCl}}, \mathrm{A} \gamma$ and $\mathrm{B} \gamma$ were regressed as a function of temperature and the resulting functions and regression coefficients are currently built into TOUGHREACT. Values of å are calculated by TOUGHREACT using effective 
ionic radii $\mathrm{r}_{\mathrm{e}, \mathrm{j}}$. Making the assumption that $\mathrm{NaCl}$ is the dominant electrolyte, and using the ion charge to determine stoichiometry coefficients, HKF Equation 125 simplifies to

$$
\begin{aligned}
& \stackrel{\circ}{\mathrm{a}}_{\mathrm{j}}=2\left(\mathrm{r}_{\mathrm{e}, \mathrm{j}}+1.91\left|\mathrm{z}_{\mathrm{j}}\right|\right) /\left(\left|\mathrm{z}_{\mathrm{j}}\right|+1\right) \text { for anions } \\
& \stackrel{\circ}{\mathrm{a}}_{\mathrm{j}}=2\left(\mathrm{r}_{\mathrm{e}, \mathrm{j}}+1.81\left|\mathrm{z}_{\mathrm{j}}\right|\right) /\left(\left|\mathrm{z}_{\mathrm{j}}\right|+1\right) \text { for cations }
\end{aligned}
$$

where the subscript $\mathrm{j}$ refers to each ion and other parameters are as defined above. The values of 1.91 and 1.81 in the above equations correspond to $\mathrm{r}_{\mathrm{e}, \mathrm{Na}}{ }^{+}$and $\mathrm{r}_{\mathrm{e}, \mathrm{Cl}}{ }^{-}$, respectively. Values of $r_{e, j}$ are input from the TOUGHREACT database and can be changed as deemed necessary in this database.

Table A.1. Estimated values of effective ionic radii $\left(r_{e, j}\right)$ currently in the TOUGHREACT thermodynamic database for species that are not reported in HKF Table 3. When available, values from HKF Table 3 are used directly instead of those shown here.

\begin{tabular}{|l|l|l|}
\hline Ion Charge & $\mathbf{r}_{\mathbf{e}, \mathbf{j}}$ & \multicolumn{1}{c|}{ Source } \\
\hline-1 & 1.81 & Cl- value \\
\hline-2 & 3.00 & Rounded average of CO3-- and SO4-- values \\
\hline-3 & 4.2 & Estimated from straight line fit with charge \\
\hline+1 & 2.31 & NH4+ value \\
\hline+2 & 2.8 & Rounded average for +2 species in HKF Table 3 \\
\hline+3 & 3.6 & Rounded average for +3 species in HKF Table 3 \\
\hline+4 & 4.5 & $\begin{array}{l}\text { Estimated using HKF Equation 142 and average } \\
\text { crystallographic radii of }+4 \text { species in CRC Handbook }\end{array}$ \\
\hline$<-3$ & & Linear Extrapolation (charge $\times 4.2 / 3.0)$ \\
\hline$>+3$ & & Linear Extrapolation (charge $\times 4.5 / 4.0)$ \\
\hline & & \\
\hline
\end{tabular}

The limits of applicability of this method depend on how well the assumption of $\mathrm{NaCl}$-dominance in solution is satisfied. Also, consistency between the activity coefficient model and the types of ion pairs included in the thermodynamic database is critical. A good example is that of the $\mathrm{NaCl}^{0}$ ion pair. HKF fitted their Debye-Huckel data assuming that no significant formation of $\mathrm{NaCl}^{0}$ took place. Excluding this ion pair 
from the thermodynamic database, the model reproduces fairly well the mean activity coefficients determined by Robinson and Stokes (1965) at $25^{\circ} \mathrm{C}$ (Figure A.1) up to at least $6 \mathrm{M} \mathrm{NaCl}$ (ionic strength 6). However, this is not true when $\mathrm{NaCl}^{0}$ and the dissociation constants from Shock et al. (1989), for example, are included in the database (at least at $25^{\circ} \mathrm{C}$ ). The reverse is true for species like $\mathrm{MgSO}_{4}$ and $\mathrm{Na}_{2} \mathrm{SO}_{4}$, for which accurate activities cannot be computed without including the $\mathrm{MgSO}_{4}$ and $\mathrm{NaSO}_{4}{ }^{-}$species in the thermodynamic database. In this case, using dissociation constants from Shock et al. (1989) for these species, and the HKF activity coefficient model discussed above, mean activities determined by Robinson and Stokes $(1965)$ at $25^{\circ} \mathrm{C}$ can be reproduced fairly well up to $2 \mathrm{M} \mathrm{MgSO}_{4}$ (ionic strength $=8$ ) and $1 \mathrm{M} \mathrm{Na}_{2} \mathrm{SO}_{4}$ (ionic strength = 3) (Figures A.2). Although no general rule can be made as to the limit of applicability of the activity coefficient model, we would not recommend using this model at ionic strengths greater than 3 or 4 , especially at higher temperatures. 

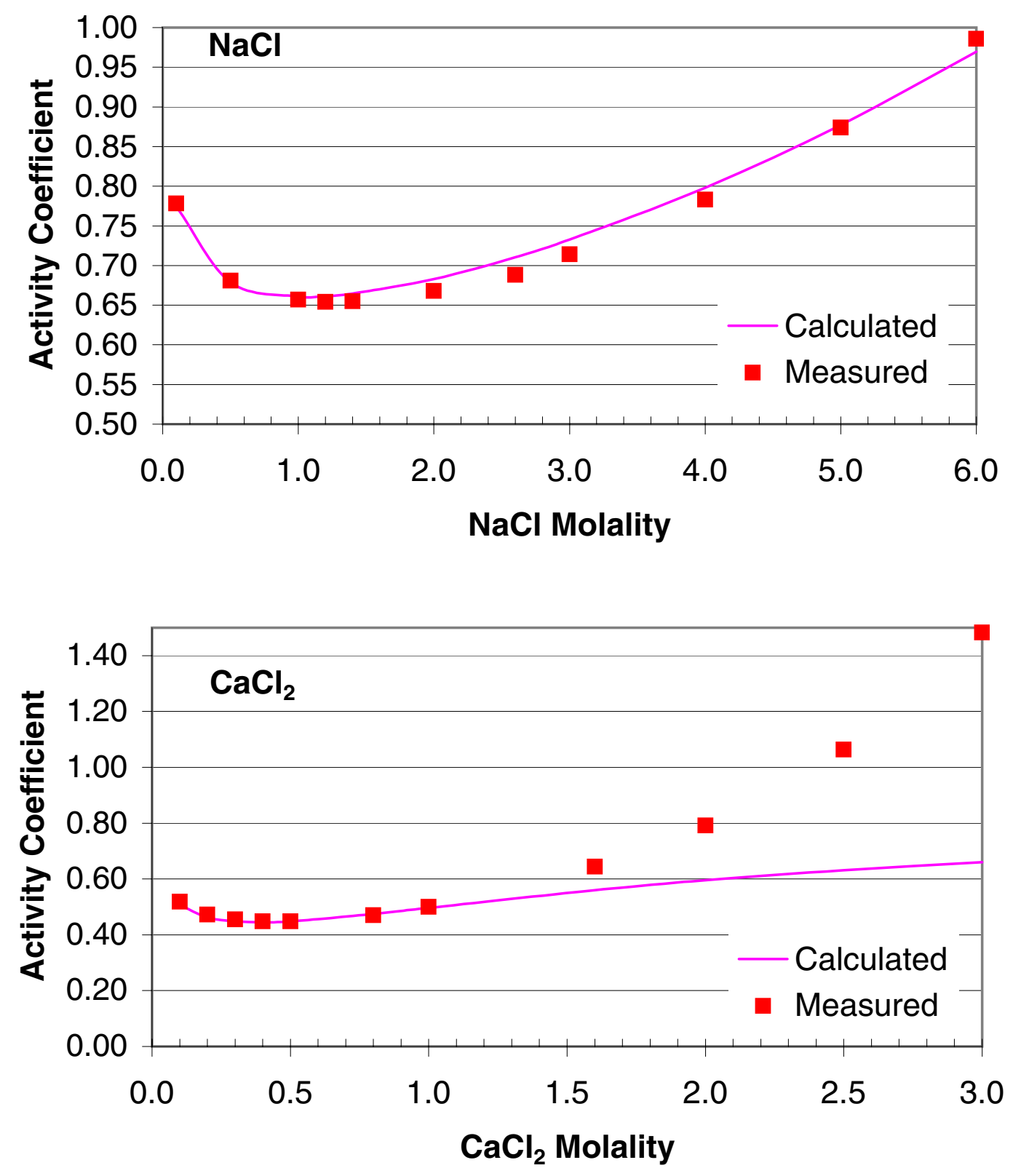

Figure A.1. Mean-ion activity coefficients of $\mathrm{NaCl}$ and $\mathrm{CaCl}_{2}$ derived from individual activity coefficients calculated with Equation A.1. Symbols represent data from measurements by Robinson and Stokes (1965). 

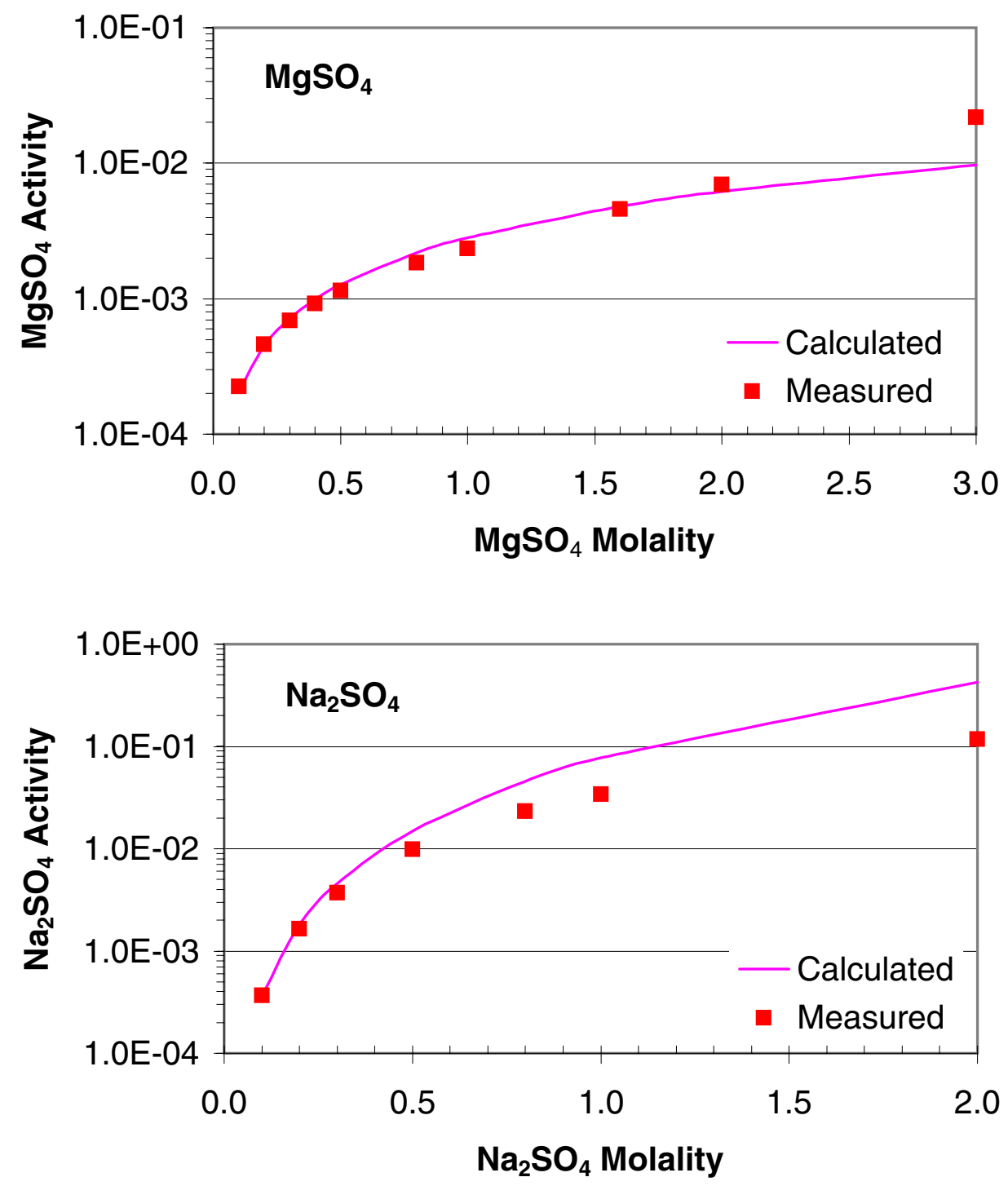

Figure A.2. Activities of $\mathrm{MgSO}_{4}$ and $\mathrm{Na}_{2} \mathrm{SO}_{4}$ derived from individual activity coefficients calculated with Equation A.1. Symbols represent data from measurements by Robinson and Stokes (1965). Actual activities, rather than activity coefficients, are compared here because significant ion association takes place. 


\section{Appendix B Formulation of the Pizter Ion-Interaction Model}

A generally accepted form of the Pitzer model was formulated in Harvie et al. (1984) and called the HMW formulation (model). This model has been implemented in TOUGREACT. In the HMW model, water activity is formulated as:

$$
\operatorname{Ln}\left(a_{H_{2} \mathrm{O}}\right)=-\frac{m_{w}}{1000}\left(\sum_{i=1}^{N} m_{i}\right) \phi
$$

where $a_{H_{2} \mathrm{O}}$ is water activity, $m_{i}$ is molality of species $i, m_{w}$ is molecular weight of water, $N$ is the number of species in the system, and $\phi$ is the osmotic coefficient, defined as:

$$
\begin{aligned}
& \sum_{i=1}^{N} m_{i}(\phi-1)=2\left(-\frac{A^{\Phi} I^{\frac{3}{2}}}{1+1.2 \sqrt{I}}\right) \\
& +\sum_{c=1}^{N_{c}} \sum_{a=1}^{N_{a}} m_{c} m_{a}\left(B_{c a}^{\Phi}+Z C_{c a}\right) \\
& +\sum_{c} \sum_{c^{\prime}=c+1} m_{c} m_{c^{\prime}}\left(\Phi_{c c^{\prime}}^{\phi}+\sum_{a=1} m_{a} \psi_{c c^{\prime} a}\right) \\
& +\sum_{a} \sum_{a^{\prime}=a+1} m_{a} m_{a^{\prime}}\left(\Phi_{a a^{\prime}}^{\phi}+\sum_{c=1} m_{c} \psi_{a a^{\prime} c}\right) \\
& +\sum_{n=1}^{N_{n}} \sum_{c=1}^{N_{c}} m_{n} m_{c} \lambda_{n c}+\sum_{n=1}^{N_{n}} \sum_{a=1}^{N_{a}} m_{n} m_{a} \lambda_{n a} \\
& +\sum_{n=1}^{N_{n}} \sum_{c=1}^{N_{c}} \sum_{a=1}^{N_{a}} m_{n} m_{c} m_{a} \zeta_{n c a}
\end{aligned}
$$

where $I$ is the ionic strength, defined as $I=\frac{1}{2} \sum_{k=1}^{N} z_{k}^{2} m_{k}$, and $z_{k}$ is the electrical charge of species $k$. The subscripts $c, a$, and $n$ denote cations, anions, and neutral species, respectively. The activity coefficients of cations $\left(\gamma_{M}\right)$, anions $\left(\gamma_{X}\right)$, and neutral species $\left(\gamma_{N}\right)$ are respectively calculated as: 


$$
\begin{aligned}
& \ln \gamma_{M}=Z_{M}^{2} F+\sum_{a=1}^{N_{a}} m_{a}\left(2 B_{M a}+Z C_{M a}\right) \\
& +\sum_{c=1} m_{c}\left(2 \Phi_{M c}+\sum_{a=1} m_{a} \psi_{M c a}\right) \\
& +\sum_{a} \sum_{a^{\prime}=a+1} m_{a} m_{a^{\prime}} \psi_{a a^{\prime} M} \\
& +\left|Z_{M}\right| \sum_{c=1}^{N_{c}} \sum_{a=1}^{N_{a}} m_{c} m_{a} C_{c a} \\
& +2 \sum_{n=1}^{N_{n}} m_{n} \lambda_{n M} \\
& \ln \gamma_{X}=Z_{X}^{2} F+\sum_{c=1}^{N_{c}} m_{c}\left(2 B_{c X}+Z C_{c X}\right) \\
& +\sum_{a=1} m_{a}\left(2 \Phi_{X a}+\sum_{c=1} m_{c} \psi_{X a c}\right) \\
& +\sum_{c} \sum_{c^{\prime}=c+1} m_{c} m_{c^{\prime}} \psi_{c c^{\prime} X} \\
& +\left|Z_{x}\right| \sum_{c=1}^{N_{c}} \sum_{a=1}^{N_{a}} m_{c} m_{a} C_{c a} \\
& +2 \sum_{n=1}^{N_{n}} m_{n} \lambda_{n X} \\
& \ln \gamma_{N}=\sum_{a=1}^{N_{a}} m_{a}\left(2 \lambda_{n a}\right)+\sum_{c=1}^{N_{c}} m_{c}\left(2 \lambda_{n c}\right) \\
& +\sum_{c=1}^{N_{c}} \sum_{a=1}^{N_{a}} m_{c} m_{a} \zeta_{N c a}
\end{aligned}
$$

where $F$ is given by:

$$
\begin{aligned}
& F=-A^{\Phi}\left(\frac{\sqrt{I}}{1+1.2 \sqrt{I}}+\frac{2}{1.2} \ln (1+1.2 \sqrt{I})\right) \\
& +\sum_{c=1} \sum_{c^{\prime}=c+1} m_{c} m_{c^{\prime}} \Phi_{c c^{\prime}}^{\prime}+\sum_{a=1} \sum_{a^{\prime}=a+1} m_{a} m_{a^{\prime}} \Phi_{a a^{\prime}}^{\prime} \\
& +\sum_{c=1}^{N_{c}} \sum_{a=1}^{N_{a}} m_{c} m_{a} B_{c a}^{\prime}
\end{aligned}
$$

$C_{M X}$ is derived from $C_{M X}^{\Phi}$ as:

$$
C_{M X}=\frac{C_{M X}^{\Phi}}{2 \sqrt{\left|z_{M} z_{X}\right|}}
$$

and $Z$ is calculated as: 


$$
Z=\sum_{k=1}^{N}\left|z_{k}\right| m_{k}
$$

The Pitzer virial coefficients, $B_{M X}^{\Phi}, B_{M X}, B_{M X}^{\prime}, \alpha_{M X}, C_{M X}, \lambda_{N C}$ and $\lambda_{N A}$ in Equation (B2) through (B7) are described below.

$B_{M X}^{\Phi}$, used to calculate the osmotic coefficient and water activity, is defined according to:

$$
B_{M X}^{\Phi}=\beta_{M X}^{(0)}+\beta_{M X}^{(1)} e^{-\alpha_{M X} \sqrt{I}}+\beta_{M X}^{(2)} e^{-\alpha_{M X}^{\prime} \sqrt{I}}
$$

where $\beta_{M X}^{(0)}, \beta_{M X}^{(1)}, \beta_{M X}^{(2)}$, and $\alpha_{M X}$ are temperature-dependent ion-interaction parameters.

$B_{M X}$ is used to calculate the activity coefficient of charged species (ions). This coefficient is calculated as:

$$
B_{M X}=\beta_{M X}^{(0)}+\beta_{M X}^{(1)} g\left(\alpha_{M X} \sqrt{I}\right)+\beta_{M X}^{(2)} g\left(\alpha_{M X}^{\prime} \sqrt{I}\right)
$$

with function $\mathrm{g}(\mathrm{x})$ defined as:

$$
g(x)=2\left(1-(1+x) e^{-x}\right) / x^{2}
$$

and x denoting $\alpha_{M X} \sqrt{I}$ or $\alpha_{M X}^{\prime} \sqrt{I}$, respectively.

$B_{M X}^{\prime}$ is used to calculate the modified Debye-Hückel term, and is formulated as:

$$
\begin{aligned}
& B_{M X}^{\prime}=\frac{\partial B_{M X}}{\partial I} \\
& =\beta_{M X}^{(1)} \frac{g^{\prime}\left(\alpha_{M X} \sqrt{I}\right)}{I}+\beta_{M X}^{(2)} \frac{g^{\prime}\left(\alpha_{M X}^{\prime} \sqrt{I}\right)}{I}
\end{aligned}
$$

with function $g^{\prime}(x)$ defined as:

$$
g^{\prime}(x)=-2\left(1-\left(1+x+\frac{x^{2}}{2}\right) e^{-x}\right) / x^{2}
$$

and $x$ denoting $\alpha_{M X} \sqrt{I}$ or $\alpha_{M X}^{\prime} \sqrt{I}$, respectively.

For any salt containing a monovalent ion, $\alpha_{M X}=2$ and $\alpha_{M X}^{\prime}=12$; for 2-2 electrolytes, $\alpha_{M X}=1.4$ and $\alpha_{M X}^{\prime}=12$; for 3-2, 4-2, and higher valence electrolytes, $\alpha_{M X}=2.0$ and $\alpha_{M X}^{\prime}=50$. 
Note that $\Phi_{c c}^{\phi}, \Phi_{a a}^{\phi}, \Phi_{c c}, \Phi_{a a}, \Phi_{c c}^{\prime}, \Phi_{a a}^{\prime}$ are interaction parameters for like-sign ionic pairs (mixing terms). They are temperature and ionic strength dependent:

$$
\begin{gathered}
\Phi_{i j}^{\phi}=\theta_{i j}+{ }^{E} \theta_{i j}(I)+I^{E} \theta_{i j}^{\prime}(I) \\
\Phi_{i j}=\theta_{i j}+{ }^{E} \theta_{i j}(I) \\
\Phi_{i j}^{\prime}={ }^{E} \theta_{i j}^{\prime}(I)
\end{gathered}
$$

Terms ${ }^{E} \theta_{i j}(I)$ and ${ }^{E} \theta_{i j}^{\prime}(I)$ are functions of the ionic charges between the pair and solution ionic strengtA. These functions are defined in Pitzer (1991) and can normally be ignored in moderately concentrated solutions of ionic strength less than 10 molal (for all like-sign pairs, ${ }^{E} \theta_{i j}(I)=0$ and $\left.{ }^{E} \theta_{i j}^{\prime}(I)=0\right)$. Also, $\theta_{i j}$ are temperature-dependent fitting parameters, with ${ }^{E} \theta_{i j}(I)$ and ${ }^{E} \theta_{i j}^{\prime}(I)$ calculated according to Pitzer (1991). $\Psi_{c c a}$ and $\Psi_{c a a}$ are the temperature dependent interaction coefficients of ternary terms. $\zeta_{n c a}$ is the temperature dependent interaction coefficient of neutral-cation-anion terms. Normally, this term is ignored (for all neutral-cation-anion triplets, $\zeta=0$ ). 